\title{
Examining price and service competition among retailers in a supply chain under potential demand disruption
}

\begin{abstract}
Supply chain disruptions management has attracted significant attention among researchers and practitioners. The paper aims to examine the effect of potential market demand disruptions on price and service level for competing retailers. To investigate the effect of potential demand disruptions, we consider both a centralized and a decentralized supply chain structure. To analyze the decentralized supply chain, the Manufacturing Stackelberg (MS) game theoretical approach was undertaken. The analytical results were tested using several numerical analyses. It was shown that price and service level investment decisions are significantly influenced by demand disruptions to retail markets. For example, decentralized decision makers tend to lower wholesale and retail prices under potential demand disruptions, whereas a proactive retailer needs to increase service level with an increased level of possible disruptions. This research may aid managers to analyze disruptions prone market and to make appropriate decision for price and service level. The manufacturer or the retailers will also be able to better determine when to close a market based on the proposed analysis by considering anticipated disruptions. The benefits and usefulness of the proposed approach are explained through a real-life case adopted from a toy supply chain in Bangladesh.
\end{abstract}

Keywords: Disruption management; price competition; service competition, demand disruptions, supply chain risk.

\section{Introduction}

Firms face ever-increasing competition at the local and international level in sustainably conducting business at a profit (Cardinali \& Bellini, 2014; Kuo 2013; Fornari, Fornari, Grandi, \& Menegatti, 2016). Within this dynamic and competitive environment, non-price 
factors such as after sales service, free gifts are equally if not more important than price factors, irrespective of whether the environment in question exists in a developed or developing countries, firms may struggle in operating business smoothly (Kumar et al., 2017; Murali, Pugazhendhi, \& Muralidharan, 2016; Sarkar, Kundu, \& Chaudhuri, 2016). Many people have had the real life experience of getting a different quality of service from two retail stores, although they may be adjacent to each other. Also, the same product can be obtained at a different price from different retail stores. Driven by this practical life experience, this research focuses on interactions between retailers related to product price and customer service. Interested readers are directed to read Lu et al. 2011; Li et al. 2012; Tsay \& Agrawal 2004 to gain further insight into service attributes in decision making in supply chains.

Supply chain success largely depends on the consumption of products from downstream supply chain agents, i.e., retailers. Customer loyalty is greatly influenced by retail price and retail services, which ultimately assists firms in building a strong brand image on top of product quality (Yuen \& Chan 2010). As such, fixing the price of products and providing demand-enhancing service, as well as ensuring exemplary after sales service, are considered to be key strategic and tactical decisions (Lu et al. 2011). Moreover, recent supply chain literature emphasizes the inclusion of disruption risk, supply chain risk and uncertainty in strategic decision making (Paul et al. 2016a; 2016b; 2017; Ali \& Nakade 2016). Otherwise, supply chain managers may be prone to decision making under the assumption of smooth business environment (Tang 2007).

A number of articles have examined the issues of price competition (Anderson \& Bao 2010; Yang et al. 2014; Opornsawad et al. 2013; Roy, Sana, \& Chaudhuri, 2015 ; Wang 2006; Wang \& Sun 2011; Willart, 2015), or focused on formulating analytical models to deal with price sensitive demand (Sana, 2011a; 2011b; 2012). However, few papers simultaneously 
consider price and service competition issues. Table 1 gives a recent scenario of price and service competition issues. When dealing with service competition, most studies assume that manufacturers are competing to provide demand-enhancing services and that they are investing in offering services (Zhao et al. 2013). It might therefore be worth exploring when retailers are competing to provide services to customers, as well as how they are bearing the cost involved in providing the services to customers. This paper investigates such insights from the theoretical and practical standpoint.

Table 1: Research considering price and service competition issues

\begin{tabular}{|c|l|c|c|c|}
\hline Sl. no. & Authors & \multicolumn{2}{|c|}{$\begin{array}{c}\text { Competition } \\
\text { Issues }\end{array}$} & \multicolumn{2}{|c|}{$\begin{array}{c}\text { Disruption- } \\
\text { focused }\end{array}$} \\
\cline { 3 - 5 } & & & Yes & No \\
\hline 1 & & Farm (2016) & Price & $\sqrt{ }$ \\
\hline 2 & Gabaix et al.(2016) & Price & $\sqrt{ }$ \\
\hline 3 & He et al. (2015) & Price & $\sqrt{ }$ \\
\hline 4 & Dan et al. (2014) & Price and service & & $\sqrt{ }$ \\
\hline 5 & Giri \& Maiti (2014) & Service & & $\sqrt{ }$ \\
\hline 6 & Mahmoodi \& Eshghi (2014) & Price & & $\sqrt{ }$ \\
\hline 7 & Wenlong et al. (2013) & Price & $\sqrt{ }$ \\
\hline 8 & Li et al. (2012) & Price and Service & & $\sqrt{ }$ \\
\hline 9 & Lin et al. (2011) & Price & & $\sqrt{ }$ \\
\hline 10 & Lowengart \& Mizrahi (2001) & Price & & $\sqrt{ }$ \\
\hline
\end{tabular}

Disruptions caused by natural and man-made actions introduce shocks into the supply chain systems, and can paralyze the supply chain (Schmitt et al. 2017). In this work, we attempt to examine price and service decisions under a state of probabilistic demand disruption. Much of the research in the literature on demand disruptions is based on coordination and contracts among supply chain partners. However, there remains a dearth of research considering numerical investigations of the impact of demand disruptions on supply chains. 
Demand disruption can occur due to loss of major customers, innovative competitors and inaccurate forecasting (Koblen \& Škurrková 2015). It is obvious and needless to say that demand is the key driver for proper functioning of the supply chain. Therefore, demand disruption significantly influences all agents in the chain (Huang et al. 2006; Wenlong et al. 2013; Xiao \& Yu 2006). Eventually, the original production, purchasing, pricing, and marketing plans must be revised in order to respond to or compensate for the demand disruption.

Cao et al. (2013) proposed a supply chain coordination mechanism with a single manufacturer and numerous retailers by utilizing revenue sharing agreements. Xiao et al. (2007) considered different scenarios to mitigate demand disruptions by considering quantity discounts. Xiao \& Qi (2008) developed the coordination mechanism and the effect of cost on this and considered quantity discount schemes.

To the best of our knowledge, price and service competition issues with potential demand disruption are rarely reported in the literature. In addition, it is evident from the literature that little attention is paid to numerical investigations of the product prices and service levels of firms while taking demand disruption into consideration. It may be meaningful to study optimal firm decisions on price and service level investments with consideration for probabilistic demand disruption. This paper aims to fill this research gap in the literature of supply chain risk management.

Markets are becoming more vulnerable due to an increase in the number of man-made and natural disruptions (Peck 2006). Therefore, research focusing on price and service competition with disruption may benefit decision makers responsible for pricing and fixing service levels for retail stores. The main contributions of our work are summarized as follows. 
- We explore the pricing and service mechanisms of multiple competing retailers under both decentralized and centralized supply chain configurations while considering potential demand disruptions at the retail market.

- Unlike most of supply chain literature, which focuses on building conceptual frameworks (Tang \& Musa 2011), or applies supply chain coordination mechanisms (Chen \& Xiao 2009; Xiao et al. 2005), we conduct a numerical investigation to inspect price and service level decisions of the supply chain members in the context of the market to provide management insights into the problem.

- We examine the effect of probability of disruptions on retail demand markets and investigate the extent and pattern of changing the price and service of a supply chain system with regard to disruptions probability.

The remaining sections of this paper are organized as follows. Section 2 presents materials and methods relevant to this research. Section 3 briefly gives the competing retailers model. In Section 4, we provide the solution methodology for fixing price and service level in centralized and decentralized supply chains. Section 5 applies the proposed method to a case supply chain in Bangladesh, and the results are illustrated therein. Finally, Section 6 concludes the research with theoretical and managerial implications.

\section{Materials and methods}

\subsection{Supply chain risk}

A supply chain network is comprised of organizations, people, technology, activities, and information. Its function is to add value to raw materials and components, and transforms them into final products for delivery to end users (Hishamuddin 2013). Thus, the activities performed in a supply chain play a major role in achieving competitive advantage for the 
stakeholders in the network.

Supply chain risk is classified into operational risk and disruption risk (Tang 2006, Wakolbinger \& Cruz 2011, Cruz 2013, Kleindorfer \& Saad 2009). Fig. 1 displays supply chain risk categorization based on the probability of risky events and the impact of such events on business.

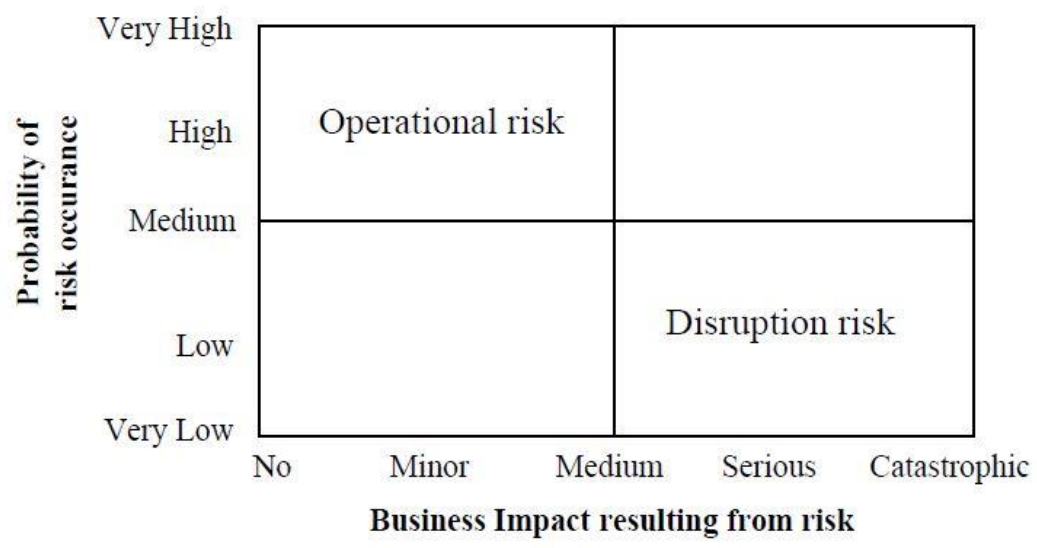

Fig.1: Categorization of supply chain risk (Brindley, 2017)

Operational risks refer to the risks faced by an organization during normal operations due to the uncertainties of demand, supply, market price, and cost (Heckmann et al., 2015). Table 2 lists some operational risks in supply chains.

Supply chain disruptions can be thought of as catastrophic events (Knemeyer et al. 2009) that can severely degrade supply chain performance (Hoffmann et al. 2013). Supply chain networks are exposed to numerous unpredictable and unforeseen disruptions (Atwater et al. 2014; Blackhurst et al. 2011). Supply chain disruptions can be caused by either natural environment disasters and uncertainties, or by human acts including political instability, quality problems, regional turbulence, and terrorism (Hishamuddin 2013; Ambulkar et al. 2015a; Cao et al. 2013).

Supply chain disruption may reduce the performance of supply chains drastically. For instance, the supply chain disruptions faced by organizations around the globe during the Taiwan earthquake of September 1999 severely impacted the global semiconductor market 
(Papadakis \& Ziemba 2001). Ericsson lost $\$ 400$ million in sales in the year 2000, and had to quit the mobile phone business when fire seized the Phillips microchip plant in New Mexico, one of the major suppliers to Ericsson (Tomlin 2006).

Table 2: Categories of operational risks in supply chains

\begin{tabular}{|c|c|c|}
\hline Operational risk & Brief description & Literature \\
\hline Capacity & $\begin{array}{l}\text { The risk related to low/high capacity of a } \\
\text { plant. This risk also includes a lack of } \\
\text { capacity flexibility. }\end{array}$ & Qin et al. (2014). \\
\hline Demand & $\begin{array}{l}\text { Risk involved in demand fluctuations or } \\
\text { demand uncertainty. The causes may involve } \\
\text { inaccurate demand forecasting or other man- } \\
\text { made or natural factors, which are external to } \\
\text { an organization. }\end{array}$ & Paul et al. (2014a). \\
\hline Information & $\begin{array}{l}\text { Information leaked or hacked, cyber-attacks } \\
\text { on supply chain players important } \\
\text { information }\end{array}$ & Bandyopadhyay et al. (2010) \\
\hline Inventory & $\begin{array}{l}\text { Risk resulting from too high or too low } \\
\text { inventory level, damage to inventory. }\end{array}$ & Guéant et al. (2013). \\
\hline Lead time & $\begin{array}{l}\text { Risk from the variability of lead time in } \\
\text { manufacturing, sourcing and delivery of } \\
\text { products. }\end{array}$ & Lin (2016). \\
\hline Price & $\begin{array}{l}\text { Risks from raw materials, finished goods ad } \\
\text { auxiliary and operating materials. }\end{array}$ & Kaufmann (2016). \\
\hline Supply & $\begin{array}{l}\text { Risk resulting from inbound supply failure or } \\
\text { supply delay, or in the absence of a multi- } \\
\text { sourcing strategy. }\end{array}$ & Lee (2015). \\
\hline Transportation & $\begin{array}{l}\text { Transportation failure, delay in } \\
\text { transportation, high transportation cost. }\end{array}$ & Hishamuddin et al. (2015). \\
\hline
\end{tabular}

Today's supply chain management is continuously focusing on increasing the efficiency of supply chain network (Atwater et al. 2014) and is having shorter lead times, less suppliers, reduced inventories, and greater globalization (Jabbarzadeh et al. 2016). These developments have resulted in leaner and cost-effective supply chains (Neiger et al. 2009; Craighead et al. 2007). However, supply chains have consequently become much more exposed to risks (Natarajarathinam et al. 2009). 


\subsection{Supply chain disruptions management}

Norrman \& Jansson (2004) defined supply chain risk management as the ability to have associates in a supply chain and to "apply risk management process tools to deal with risks and uncertainties caused by, or impacting on, logistics related activities or resources" (p. 436).

The concept of managing supply chain risk is an established concept (Ho et al. 2015). In fact, where there is a supply chain, whether it is operating at the local (Rogers et al. 2016; Elzarka 2013) or global level (Tse et al. 2016; Cruz 2013; Oehmen et al. 2009), there are inherent risks. In order to remain competitive in a vulnerable environment, supply chains need to be examined to mitigate against potential risks. Thus, numerous researchers have recently pursued supply chain risk management research (Aqlan \& Lam 2015; Srivastava et al. 2015; Singhal \& Singhal 2012; Samvedi et al. 2013; Tang \& Musa 2011).

There are two approaches, seen in both the academic literature and in practice, to mitigating supply chain disruptions; the proactive approach and the reactive approach (Natarajarathinam et al. 2009). Table 3 gives an overview of proactive and reactive approaches employed in the recent literature to mitigate the effect of supply chain disruptions.

Table 3: Proactive and reactive approaches to disruption management

\begin{tabular}{|l|l|l|l|}
\hline Sl. no. & Authors & Approach used & Domain of application \\
\hline 1 & Chung et al. (2015) & Proactive approach & $\begin{array}{l}\text { Express logistics supported by } \\
\text { air transportation. }\end{array}$ \\
\hline 2 & Marley et al. $(2014)$ & Reactive approach & Steel processing plants. \\
\hline 3 & Schmitt et al. (2016) & Reactive approach & $\begin{array}{l}\text { Four-echelon supply chain } \\
\text { including assembly. }\end{array}$ \\
\hline 4 & Sawik (2016) & Proactive-reactive & $\begin{array}{l}\text { Supplier selection with a focus on } \\
\text { disruption management. }\end{array}$ \\
\hline 5 & Tse et al. (2016) & Proactive approach & Thai beverage industry. \\
\hline
\end{tabular}


Disruptions are uncertain as they are probabilistic in nature (Wenlong et al. 2013). Retail markets may be analyzed and predicted accordingly by considering the uncertainty associated with disruptions. Reactive strategies need time to recover from disruption and delayed response to disruptions can cause severe financial and reputational harm to firms, such as in the case of Philips/Ericsson. Therefore, proactive strategy may be beneficial to firms in achieving their goals (Norrman \& Jansson 2004).

\subsection{Supply chains with centralization and decentralization}

Maximizing total supply chain profit is the goal of the centralized supply chain (Jonsson et al. 2013). The integration of different stages of supply chain is maximized in a CSC because information redundancy is minimized. The underlying concept of centralization is the ability to receive, maintain and complete all processes, and thus maximize the profit of the whole supply chain system.

In a centralized setting, the profits of all the retailers and manufacturers are cumulative. Suppose $\pi_{i}$ is the profit for retailer i, $\pi_{m}$ is the manufacturer's profit, and $\pi_{s c}$ is the profit of the total supply chain. Thus, we have

$$
\pi_{s c}=\sum_{i} \pi_{i}+\pi_{m}
$$

Under decentralized settings, each participant of the supply chain seeks to capitalize their own interest and profit, and there is competition rather than cooperation among the supply chain members (Ali \& Nakade 2016). Game theory is often used for the optimization of decentralized supply chains (Lu et al. 2012). Competitiveness among the manufacturers and retailers can be solved using the Nash Equilibrium (Nagurney et al. 2015; Chen et al. 2017), while collaborations among supply chain partners are seen as difficult in Stackelberg games (Basar, 2010).

In the game theory approach, the comparative power of bargaining controlled by each 
firm is based on its leader-follower relationship to the other firms in the supply chain. The firm holding more power for bargaining is termed as Stackelberg leader, who has more competitive advantage. A firm with less power typically responds to leader's resolutions. For instance, in the MS game (Liu et al. 2016, Lu et al. 2011), manufacturers determine wholesale prices. The retailers notice the decisions made by the manufacturer and reply to those decisions by selecting retail prices. In the RS game (Lu et al. 2011), decision orders are reversed. Figures $2 \mathrm{a}$ and $2 \mathrm{~b}$ graphically and formulaically depict the MS and RS Games, respectively.

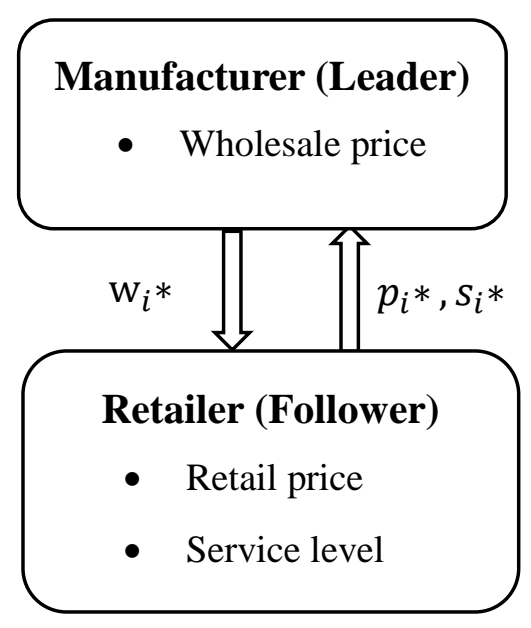

Fig. 2a: Manufacturer Stackelberg

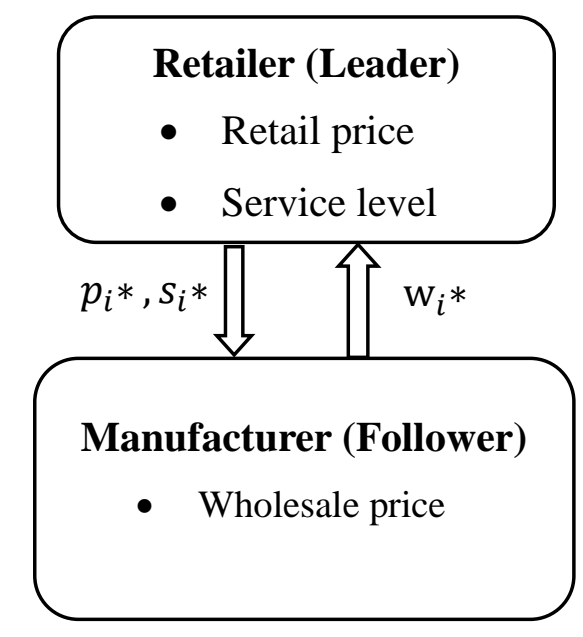

Fig. 2b: Retailer Stackelberg

This paper studies and applies the Manufacturing Stackelberg game where the manufacturer has leader role and the retailer has follower role. The leader wants to maximize their profit with the information provided by the followers' response function. We can solve the problem by following the method of 'backward induction'. The manufacturer solves the retailer's reaction function basing the fact that the retailers already know the wholesale price. From a specified wholesale price, $w_{i}^{*}$, the retailers choose their retail price, $p_{i}{ }^{*}$, and service level, $s_{i}{ }^{*}$, in order to have their equilibrium profit maximized. Assuming that all the retailers move simultaneously in a market. Therefore, we have the following conditions: 


$$
\begin{aligned}
& p_{i}^{*} \in \operatorname{argmax}_{p_{i}} \pi_{i}\left(p_{i}, p_{j}{ }^{*} \mid w_{i}, w_{j}\right) \\
& {s_{i}}^{*} \in \operatorname{argmax}_{s_{i}} \pi_{i}\left(s_{i}, s_{j}{ }^{*} \mid w_{i}, w_{j}\right)
\end{aligned}
$$

Solving the above two conditions gives $p_{i}, p_{j}, s_{i}, s_{j}$. From the reaction functions of the retailers, the manufacturer chooses their wholesale price using the following relationship:

$$
w_{i}^{*} \in \operatorname{argmax}_{w_{i}} \pi_{m}\left(w_{i}, w_{j}^{*} \mid p_{i}, p_{j}, s_{i}, s_{j}\right)
$$

Vertical Nash theory means consumers receive more service in the case where every supply chain member possess an equal proportion of the total bargaining power.

\section{Competing retailer's model}

The competing retailer's model for a supply chain consisted of one supplier $M$ and many retailers, $N$, is $R_{1 \leq i \leq N}$, is shown in Figure 3. The supplier, $S$, charges retailer, $R_{i}$, a wholesale price, $w_{i}$ for the product. Each retailer, $R_{i}$, chooses their retail price, $p_{i}$, and service level, $s_{i}$. The demand, $D_{i}$ depends on the price vector, $\mathrm{p}=\mathrm{p}_{1}, \mathrm{p}_{2}, \ldots, \mathrm{p}_{\mathrm{N}}, \mathrm{i} \neq \mathrm{j}$, and service level vector, $s=s_{1}, s_{2}, \ldots, s_{N}, i \neq j$. The demand function is assumed to depend on price and demand stimulates the required service level. The demand function for each supply chain member is linear in self-price, cross-price, self-service and competitors`service levels, but has heterogeneous parameters for all of the retailers, $R_{i}$, under consideration. In addition, market demand functions for each retailer are increasing in competitors' price and self-service level and decreasing in self-price and competitors`service level. This type of linear demand functions including similar assumptions are widely reported in the economics and supply chain literature. Interested readers are directed to the works of Lu et al. (2011); Hua et al. (2010); Huang \& Swaminathan (2009); and Huang et al. (2012) for further details. 


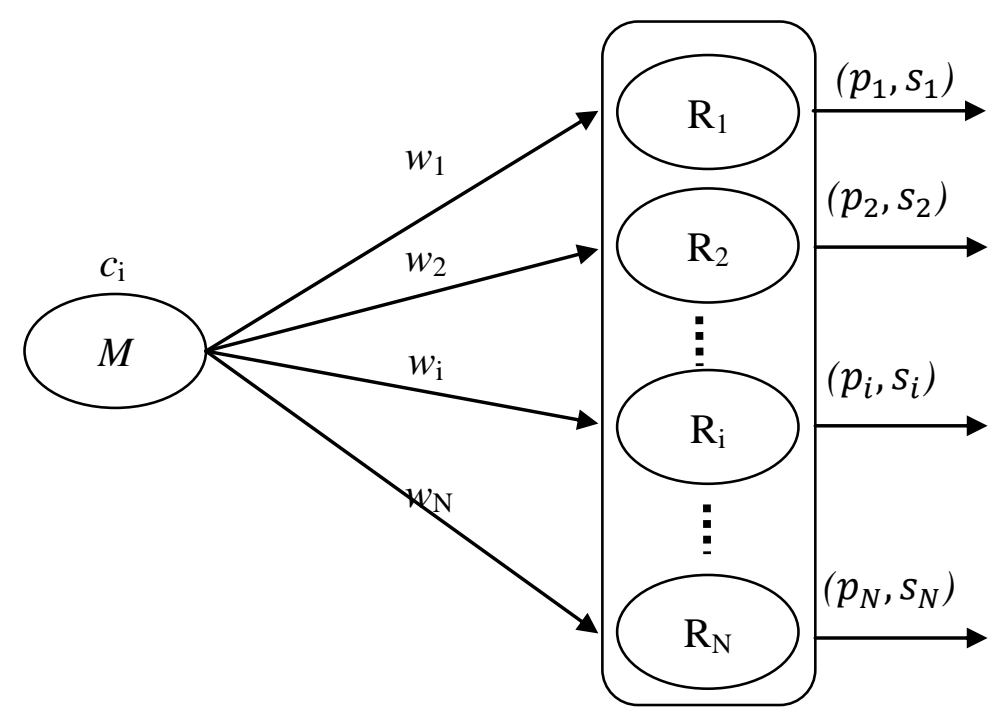

Fig. 3: Competing retailers model

Without loss of generality, and for the purpose of facilitating ease of computations of the studied model, we study a supply chain composed of two retailers and one manufacturer. Thus, we have the following demand function:

$D_{i} p_{i,} p_{j,} s_{i} s_{j}=\alpha_{i}-\beta_{i} P_{i}+\gamma_{i} P_{j}+\delta_{i} s_{i}-\theta_{i} s_{j,} i \neq j$

Here, $\beta_{i}$, and $\gamma_{i}$ represent the self- and cross-price elasticity of demand, respectively; $\delta_{i}$ measures market demand responsiveness to $\mathrm{i}^{\text {th }}$ retailer's service level; and $\theta_{i}$ is the intensity of competition in terms of service provision to their customers. $\beta_{i}, \gamma_{i}, \delta_{i}, \theta_{i}>0$ and $\beta_{i}>\gamma_{i}$, $\delta_{i}>\theta_{i}$ for $\forall \mathrm{i}$. If $k$ denotes the marginal cost required to attain the service level $s$, then the associated service providing cost is represented by $k \frac{s_{i}{ }^{2}}{2}$ (Lu et al. 2011; Tsay \& Agrawal 2004). Diminishing returns appears to occur naturally if the service includes a substantial inventory level component. According to Tsay \& Agrawal (2000), "under the assumption of standard inventory models, moving from $97 \%$ to $99 \%$ fill rate typically requires a greater incremental investment than does moving from $95 \%$ to $97 \%$. For other concepts of service, we presume that a rational manager will always target the 'lowest hanging fruit', so that subsequent improvements are progressively more difficult" (P. 375).

Using the demand function, and with the inclusion of the service cost, we have the following profit functions for the retailers in a supply chain system:

$\pi_{i}=\left(p_{i}-w_{i}\right) D_{i}-\mathrm{k} \frac{s_{i}^{2}}{2}, \forall \mathrm{i} \in \mathrm{N}$ 


$$
=\left(p_{i}-w_{i}\right)\left(\alpha_{i}-\beta_{i} P_{i}+\gamma_{i} P_{j}+\delta_{i} s_{i}-\theta_{i} s_{j}\right)-\mathrm{k} \frac{s_{i}^{2}}{2}
$$

The manufacturer profit function is given by:

$$
\begin{aligned}
\pi_{m} & =\sum_{i=1}^{N}\left(\left(w_{i}-c_{i}\right) D_{i}\right) \\
& =\sum_{i=1, i \neq j}^{N}\left(\left(w_{i}-c_{i}\right) \alpha_{i}-\beta_{i} P_{i}+\gamma_{i} P_{j}+\delta_{i} s_{i}-\theta_{i} s_{j}\right)
\end{aligned}
$$

In addition, the total supply chain profit will be:

$$
\begin{aligned}
\pi_{s c} & =\pi_{i}+\pi_{m}, \\
& =\sum_{i=1}^{N}\left(p_{i}-w_{i}\right) D_{i}-\mathrm{k} \frac{s_{i}{ }^{2}}{2}+\sum_{i=1}^{N}\left(\left(w_{i}-c_{i}\right) D_{i}\right)
\end{aligned}
$$

\section{Setting optimal price and service level investment under demand disruptions}

Pricing and service strategies are formulated for the two retailers while emphasizing demand disruptions. The probability of demand disruption for $i^{\text {th }}$ retail market is denoted by $\varphi_{i}$ here. Moreover, when a disruption happens in the retail market, it stimulates changes in the market scale $\alpha_{i}$ for $i=1,2 . \alpha_{i}$ indicates the maximum possible demand when the products in question are offered free of charge. Management determines $\alpha_{i}$ based on demand forecasting. In this study, the effect of disruptions is captured by $\Delta \alpha_{\mathrm{i}}$. Thus, the new market scale in the event of disruptions is $\alpha_{i}=\alpha_{i}+\Delta \alpha_{i}$. The change of demand $\Delta \alpha_{i}$ can be characterized as deterministic (Wenlong et al. 2013; Xiao \& Qi 2008) or stochastic (Xiao \& Choi 2010). The demand functions after disruptions are therefore:

$\bar{D}_{1}=\left(\alpha_{1}+\Delta \alpha_{1}\right)-\beta_{1} P_{1}+\gamma_{1} P_{2}+\delta_{1} s_{1}-\theta_{1} s_{2}$

$\bar{D}_{2}=\left(\alpha_{2}+\Delta \alpha_{2}\right)-\beta_{2} P_{2}+\gamma_{2} P_{1}+\delta_{2} s_{2}-\theta_{2} s_{1}$

\subsection{A decentralized supply chain environment with demand disruption}

For a decentralized supply chain, every supply partner wants to have their own profit maximized. Considering potential demand disruptions, the manufacturer's and retailer's 
profit can be given by:

$$
\begin{aligned}
& \bar{\pi}_{m}=\sum_{i=1, j=3-i}^{2}\left[\left(w_{i}-c_{i}\right) \bar{D}_{i} \varphi_{i}+\left(w_{i}-c_{i}\right) D_{i} 1-\varphi_{i}\right] \\
& i=1,2 \text { and } j=3-i
\end{aligned}
$$

Further:

$\bar{\pi}_{i}=\left(p_{i}-w_{i}\right)\left(\left(\alpha_{i}+\Delta \alpha_{i} \varphi_{i}\right)-\beta_{i} P_{i}+\gamma_{i} P_{j}+\delta_{i} s_{i}-\theta_{i} s_{j}\right)-\mathrm{k} \frac{s_{i}^{2}}{2}$

We now apply the MS game theoretical approach (See sub-section 3.1) to derive retail price, retail service and wholesale price under non-disrupted conditions. The detailed methodology of the MS game can be found in Yang et al. (2015); Yang \& Zhou (2006); and Yu et al. (2009).

\subsection{A centralized supply chain with demand disruption}

In a centralized supply chain, we are fascinated in maximizing the total supply chain profit Thus we have:

$$
\begin{aligned}
& \bar{\pi}_{s c}=\sum_{i=1, j=3-i}^{2}\left[\left(p_{i}-c_{i}\right) \alpha_{i}+\Delta \alpha_{i}-\beta_{i} P_{i}+\gamma_{i} P_{j}+\delta_{i} s_{i}-\theta_{i} s_{j} \varphi_{i}+\left(p_{i}-c_{i}\right) D_{i} 1-\varphi_{i}\right]- \\
& \frac{k}{2} \sum_{i=1}^{2} s_{i}{ }^{2}
\end{aligned}
$$

Differentiating with $P_{i}$ and $s_{i}$ and then putting them equal to zero gives:

$$
\begin{aligned}
& \frac{\partial \bar{\pi}_{s c}}{\partial \mathrm{p}_{\mathrm{i}}}=0=\varphi_{i}\left(\alpha_{i}+\Delta \alpha_{i}-\beta_{i} p_{i}+\gamma_{i} p_{j}+\delta_{i} s_{i}-s_{j} \theta_{i}\right)-\left(\varphi_{i}-1\right)\left(\alpha_{i}-\beta_{i} p_{i}+\gamma_{i} p_{j}+\delta_{i} s_{i}-\right. \\
& \left.s_{j} \theta_{i}\right)-\beta_{i}\left(c_{i}-p_{i}\right)\left(\varphi_{i}-1\right)+\gamma_{j}\left(c_{j}-p_{j}\right)\left(\varphi_{j}-1\right)+\beta_{i} \varphi_{i}\left(c_{i}-p_{i}\right)-\gamma_{j} \varphi_{j}\left(c_{j}-p_{j}\right)
\end{aligned}
$$

$$
\begin{aligned}
& \frac{\partial \bar{\pi}_{s c}}{\partial s_{\mathrm{i}}}=0=\delta_{i}\left(c_{i}-p_{i}\right)\left(\varphi_{i}-1\right)-k s_{1}-\theta_{j}\left(c_{j}-p_{j}\right)\left(\varphi_{j}-1\right)-\delta_{i} \varphi_{i}\left(c_{i}-p_{i}\right)+ \\
& \varphi_{j} \theta_{j}\left(c_{j}-p_{j}\right)
\end{aligned}
$$

Solving these two equations yields the price levels $p_{1}, p_{2}$ and service levels $s_{1}, s_{2}$ for the decentralized supply chain case. Note that the second order conditions and the negative definite Hessian matrix must be checked to determine the optimal solution. For further details, readers are referred to Lu et al. (2011). 


\section{Application of the proposed approach}

We deliberate the results obtained from the application of the proposed approach to a representative supply chain in Bangladesh. We consider a toy supply chain, which comprises one manufacturer and two retailers, for this purpose. For convenience, we include the scenario with $\alpha_{1}=\alpha_{2}=20$, and demand disruption magnitude $\nabla \alpha_{1}=\nabla \alpha_{2}=-3$. In analyzing competitive behavior among retailers, similar simplifying assumptions are shown in the literature (e.g., Yang \& Zhou 2006).

We first numerically compute wholesale price, retail price, retail service level and optimal profit for both the centralized and decentralized settings with and without in a state of demand disruptions. We use deterministic demand disruption values in the present work. Table 4 represents the obtained results under various supply chain parameters. To simplify the experiment, we assume some parameter values to be equal. The values of those parameters are $c_{1}=c_{2}=1, \quad \beta_{1}=\beta_{2}=1, \quad \gamma_{1}=\gamma_{2}=0.6, \quad \delta_{1}=\delta_{2}=1, \theta_{1}=\theta_{2}=0.7$, $\varphi_{1}=\varphi_{2}=0.20$. Assuming identical parameters can enhance the comparison of the decision variables, and enable managerial insights (Zhao \& Wei 2012). We assume the service cost coefficient $k=0.8$. It is noted that, under such assumed symmetrical conditions, the decision parameters become equal (Opornsawad et al. 2013) i.e., $\mathrm{w}_{1}=w_{2}, \mathrm{p}_{1}=\mathrm{p}_{2}$ and $\mathrm{s}_{1}=\mathrm{s}_{2}$. Therefore, the wholesale and retail prices and retail services are included only once in Table 4. It is also worth mentioning that the solutions obtained are the Nash equilibrium wholesale and retail prices and retail services in a decentralized setting under the MS scenario. Conversely, for a centralized setting, the retail prices and retail services imply optimal prices and services that maximize total profit of the whole supply chain.

Table 4 presents the reduction of profit observed when comparing normal and fluctuating demand conditions. The supply chain maximizes profit when the players are engaged in a centralized environment with no disruptions, whereas a significant drop in profit is evident in 
every alternative scenario. It can be observed that the profit decreases by $7.91 \%$ when disruptions occur into the centralized supply chain. Similarly, the manufacturer`s and the retailers' profit are decreased by 6.02 and $6.10 \%$, respectively, when the supply chain experiences demand disruptions. These findings reflect the significance disruptions as well as the need for revision of pre-disruption decision variables in the supply chain planning process. The benefit and usefulness of revising pre-disruption supply chain decisions are described by Paul et al. (2015a; 2015b; 2014b).

Table 4: Wholesale and retail price, retail service and optimal profit for several supply chain

\begin{tabular}{|c|c|c|c|c|c|}
\hline Supply chain attributes & $\begin{array}{c}\text { Wholesale } \\
\text { price }\end{array}$ & $\begin{array}{l}\text { Retail } \\
\text { price }\end{array}$ & $\begin{array}{l}\text { Retail } \\
\text { service }\end{array}$ & $\begin{array}{c}\text { Optimal } \\
\text { profit }\end{array}$ & $\begin{array}{c}\text { Change in } \\
\text { profit }\end{array}$ \\
\hline $\begin{array}{l}\text { Centralized, no } \\
\text { disruptions }\end{array}$ & - & 29.51 & 10.70 & 570.184 & - \\
\hline Centralized, disruptions & - & 28.64 & 10.36 & 525.091 & $-7.91 \%$ \\
\hline \multirow[t]{2}{*}{$\begin{array}{l}\text { Decentralized, no } \\
\text { disruptions }\end{array}$} & \multirow[t]{2}{*}{25.50} & \multirow[t]{2}{*}{35.06} & \multirow[t]{2}{*}{11.95} & $468.490(\mathrm{~m})$ & - \\
\hline & & & & $\begin{array}{c}34.28 \\
\text { (i) }\end{array}$ & - \\
\hline \multirow[t]{2}{*}{$\begin{array}{l}\text { Decentralized, } \\
\text { disruptions }\end{array}$} & \multirow[t]{2}{*}{24.75} & \multirow[t]{2}{*}{34.02} & \multirow[t]{2}{*}{11.59} & $440.278(\mathrm{~m})$ & $\begin{array}{c}-6.02 \% \\
(\mathrm{~m})\end{array}$ \\
\hline & & & & $\begin{array}{l}32.19 \\
\text { (i) }\end{array}$ & $\begin{array}{c}-6.10 \% \\
\text { (i) }\end{array}$ \\
\hline
\end{tabular}

In this part of the study, we are interested in exploring how potential demand disruptions influence supply chain decisions from the viewpoint of a proactive decision-making environment in a supply chain system. We, therefore, present numerical investigations considering different combinations of probability of demand disruptions under both centralized and decentralized supply chain scenarios. Assuming that the probability of 
demand disruptions, $\varphi_{1}$ is varied from 0 to 1 , and $\varphi_{2}=0.1$. Since we consider symmetric data, it is sufficient to examine the nature and pattern of the decision variables under demand fluctuations by varying the disruptions probability for only the first retailer.

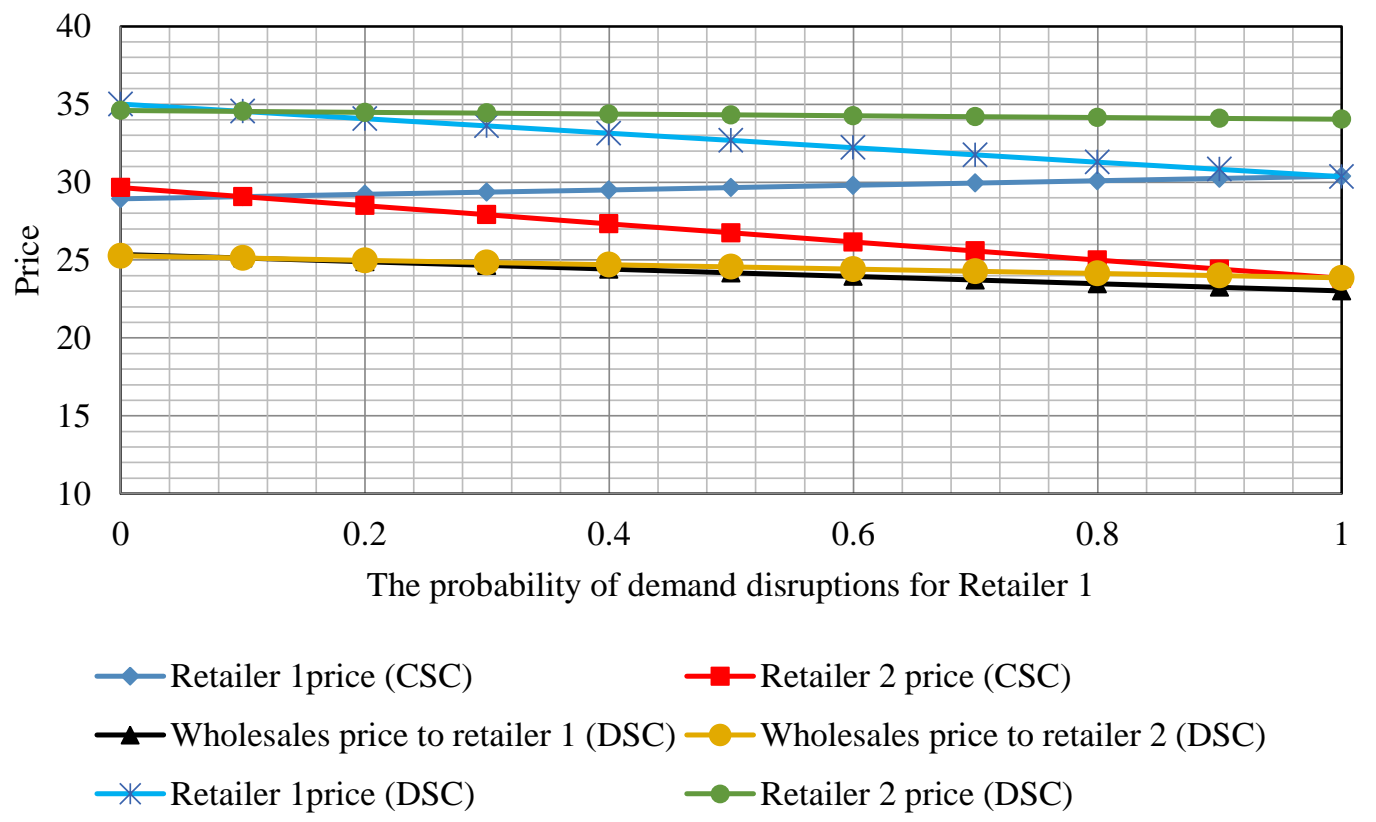

Fig. 4: The wholesale and retail price for Retailer 1

Figure 4 shows that in the decentralized setting, the supplier and the retailer who suffers demand disruptions all tend to lower the wholesale and retail prices, which are proportional to the probability of demand disruptions. This observation aligns with the findings of Wenlong et al. (2013). When the demand for the retail market drops, the retailer associated with the retail market decreases the retail price in order to increase product sales. 


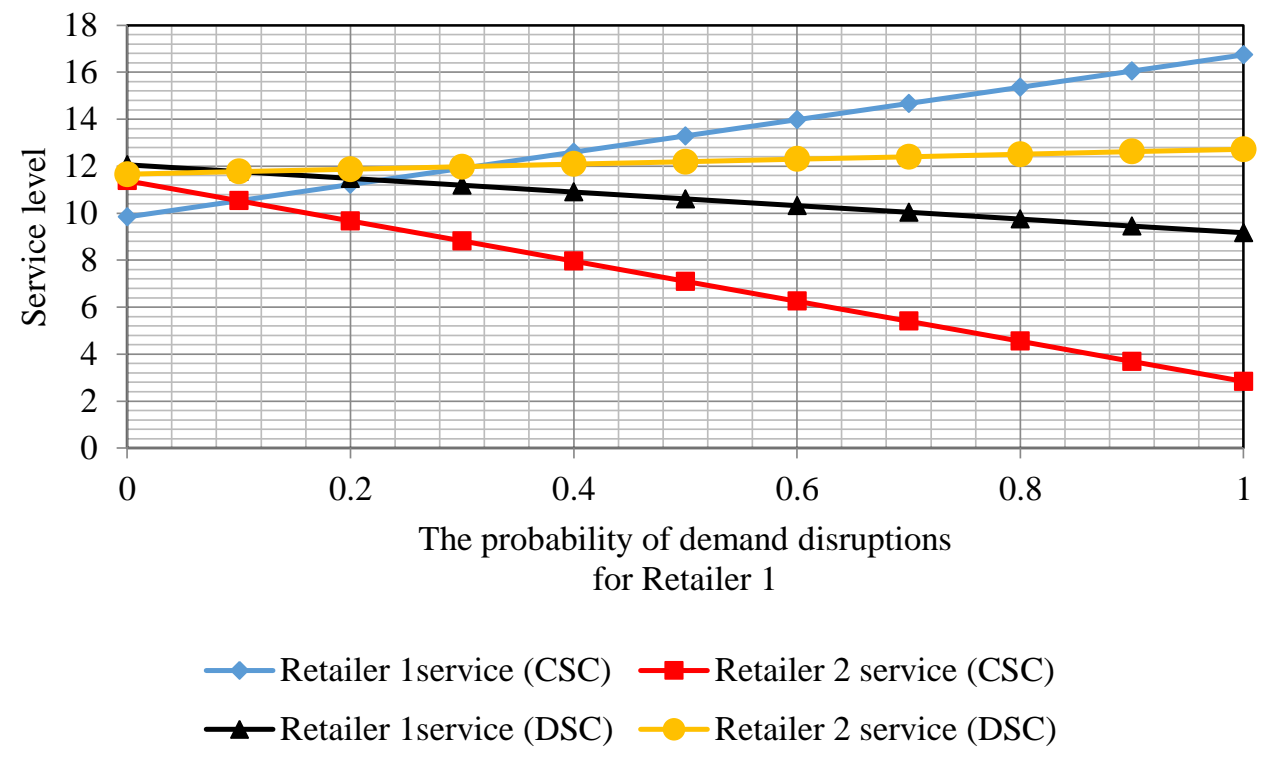

Fig. 5: The service level for Retailer 1

Figure 5 shows that, when Retailer 1 lowers their service level to compensate for the severity of increased disruptions, Retailer 2 tends to increase their service level. As both of the retailers are competing to be able to provide higher service levels, the retailers are prompted to increase the service level in order to hold more customers in the market.

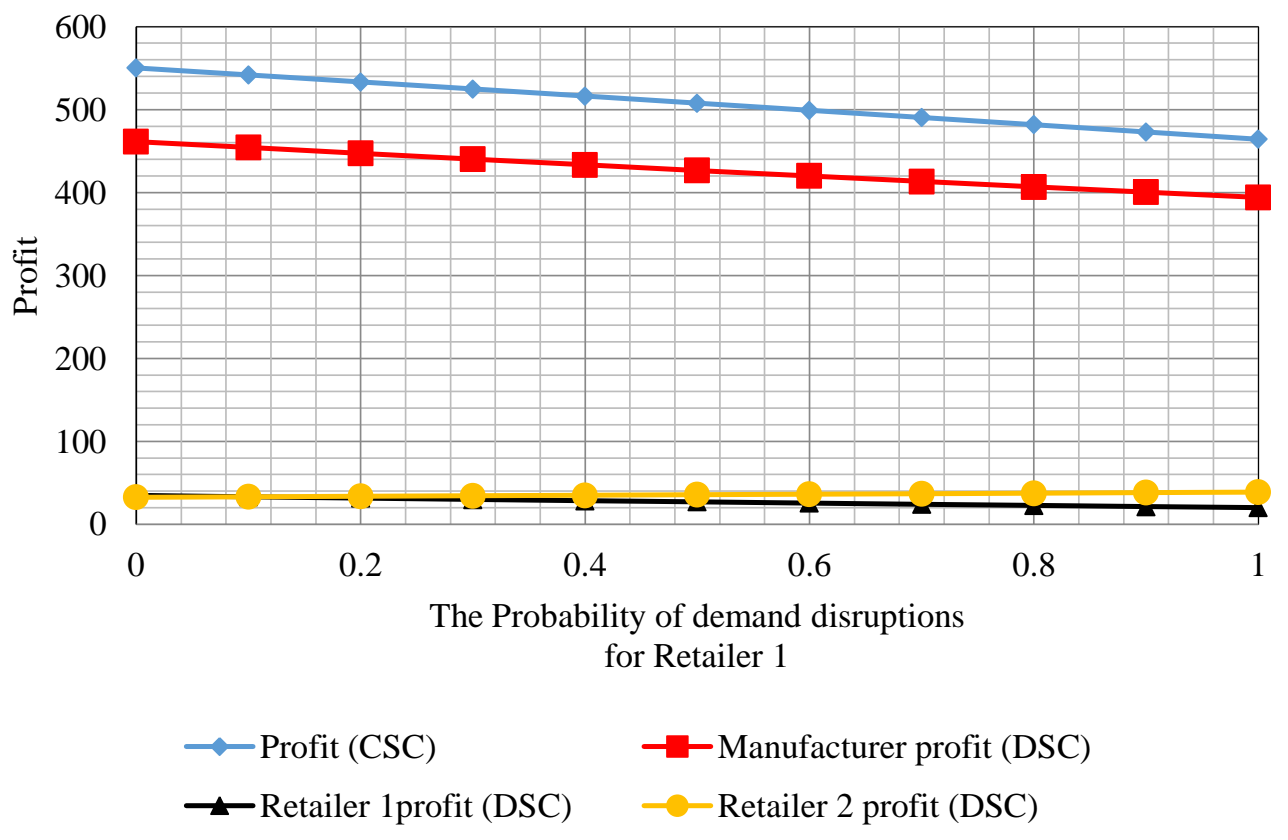

Fig. 6: The profit for Retailer 1 
Figure 6 shows that the profit for the centralized setting and for the players in the decentralized setting tends to decrease with increasing disruptions. Moreover, the profits of the centralized system seem to be higher than those of the decentralized configuration of the chain, even in the case of demand disruptions. Whether or not a supply chain undergoes disruptions, the centralized supply chain setting produces more profit or becomes more efficient than the corresponding decentralized supply chain, as shown in the supply chain literature ( e.g., Ali \& Nakade 2016).

\section{Conclusions, implications, and recommendations for future research}

Research focusing on price and service related issues is an expanding research stream in the economics and supply chain literature, as well as in commercial business practice. In a disrupted supply chain environment, the significance of and requirements for pricing and servicing strategy are assorted and increasingly demanding.

This paper presents a numerical examination of the effect of demand disruption on pricing and service strategies of the supply chain under both centralized and decentralized supply chain scenarios. In the numerical calculations, we considered different demand disruption probabilities, and examined the behavior of the model in terms of pricing, service, and profit of the supply chain members. The analysis revealed that the original pricing and servicing strategy needs to be adjusted to mitigate the effect of demand disruptions.

This work provides a basis for further study in the area of supply chain disruptions. From an academic perspective, this work uniquely contributes to the literature by recognizing the revision of price and service level investment by retailers in response to disruptions. Most of the previous studies considered one-manufacturer-one-retailer supply chains when focusing on price and service level decisions. In fact, most of the studies concentrated on price factor only when dealing with issues related to competition (Wenlong et al. 2013; Xiao \& Qi 2008). This research has first developed a model that numerically examine price and service level 
decisions based on a Manufacturing Stackelberg game theory approach. In addition, this studies relaxes the assumption, used in previous studies (e.g., Lu et al. 2011; Zhao et al. 2013), that manufacturers in competition with one another bear the costs of demand stimulated service levels. Our research diverts this cost to retailers in competitions in contrast to Lu et al. (2011) and Zhao \& Wei (2012).

Managers need to respond quickly to mitigate the effect of disruptions, including natural, man-made and financial disasters (Chowdhury \& Quaddus 2015; Liu \& Nagurney 2011; Kim \& Park 2014). This research can help managers answer two questions: 1. how do we fix prices in a competitive environment with disruption? 2. What amount should be invested in non-price factors, such as offering better service to the customer, door-to-door maintenance and developing good relationships with customers in anticipation of market disruptions? From a centralized and decentralized supply chain perspective, this paper answers these questions. Decision makers can use this research as a guide to assist them to formulate response measures to disruptions, including price and service level decisions. This research analyzes both customers and markets that suffer frequent demand disruptions. Therefore, our results may inform retail markets in Japan, Indonesia, and Bangladesh, where disruptions due to natural and man-made disaster are common (Chiu \& Small 2016; Siddiqi 2015; Mills et al. 2011; Tweed \& Walker 2011).

The research presented here could be extended in the following direction within the scope of disruptions management research:

- Methodological extension: This study examined the competitive behavior among retailers by employing only the Manufacturing Stackelberg parameters. Retailer Stacklelberg and Vertical Nash (Zhang et al. 2015) could also be tested under similar experimental conditions. 
- Inclusion of multiple retailers: Real-life supply chains consist of multiple retailers. The research will be more appealing to supply chain practitioners if it includes multiretailer supply chains or multi-echelon supply chains (Pal et al. 2012; 2014). However, it is a major challenge to be able to incorporate the computational complexity that would arise under such settings.

- Comparison of results with other competitive behaviors: Apart from Stackelberg theory, there are two others competitive behaviors, namely Cournot and Collusion (Yang \& Zhou 2006). These two competitive behaviors could be examined, and the results could be compared under similar settings.

The research proposed here could possibly be applied to any industrial domain to explore disruption prone markets and to optimize the price and service level investment decisions of supply chain players. The research also provides a foundation for academics to further investigate and extend the research in this field.

\section{References}

Ali, S. M., \& Nakade, K. (2014). Scenario-based Supply Chain Disruptions Management Framework-A Quantitative Approach. Innovation and Supply Chain Management, 8(3), 81-91.

Ali, S. M., \& Nakade, K. (2015). A Mathematical Optimization Approach to Supply Chain Disruptions Management Considering Disruptions to Suppliers. Operations and Supply Chain Management, 8(2), 57-66.

Ali, S. M., \& Nakade, K. (2016). Coordinating a supply chain system for production,pricing and service strategies with disruptions. Internation Journal of Advanced Operations Management, 8(1), 17-37.

Ambulkar, S., Blackhurst, J., \& Grawe, S. (2015). Firm's resilience to supply chain disruptions: Scale development and empirical examination. Journal of Operations Management, 33, 111-122.

Anderson, E. J., \& Bao, Y. (2010). Price competition with integrated and decentralized supply chains. European Journal of Operational Research, 200(1), 227-234.

Aqlan, F., \& Lam, S. S. (2015). Supply chain risk modelling and mitigation. International 
Journal of Production Research, 53(18), 5640-5656.

Atwater, C., Gopalan, R., Lancioni, R., \& Hunt, J. (2014). Measuring supply chain risk: Predicting motor carriers' ability to withstand disruptive environmental change using conjoint analysis. Transportation Research Part C: Emerging Technologies, 48, 360378.

Bandyopadhyay, T., Jacob, V., \& Raghunathan, S. (2010). Information security in networked supply chains: Impact of network vulnerability and supply chain integration on incentives to invest. Information Technology and Management, 11(1), 7-23.

Basar, T. (2010). Lecture notes on non-cooperative game theory. Game Theory Module of the Graduate Program in Network Mathematics, 3-6.

Blackhurst, J., Dunn, K. S., \& Craighead, C. W. (2011). An empirically derived framework of global supply resiliency. Journal of Business Logistics, 32(4), 374-391. https://doi.org/10.1111/j.0000-0000.2011.01032.x

Brindley, C. (2017). Supply chain risk, Routledge, New York, USA.

Cao, E., Wan, C., \& Lai, M. (2013). Coordination of a supply chain with one manufacturer and multiple competing retailers under simultaneous demand and cost disruptions. International Journal of Production Economics, 141(1), 425-433.

Cardinali, M. G., \& Bellini, S. (2014). Interformat competition in the grocery retailing. Journal of Retailing and Consumer Services, 21(4), 438-448. http://doi.org/10.1016/j.jretconser.2014.03.005

Chen, K., \& Xiao, T. (2009). Demand disruption and coordination of the supply chain with a dominant retailer. European Journal of Operational Research, 197(1), 225-234.

Chen, X., Wang, X., \& Chan, H. K. (2017). Manufacturer and retailer coordination for environmental and economic competitiveness: A power perspective. Transportation Research Part E: Logistics and Transportation Review, 97, 268-281.

Chowdhury, M. M. H., \& Quaddus, M. A. (2015). A multiple objective optimization based QFD approach for efficient resilient strategies to mitigate supply chain vulnerabilities: The case of garment industry of Bangladesh. Omega, 57, 5-21. Journal Article.

Craighead, C. W., Blackhurst, J., Rungtusanatham, M. J., \& Handfield, R. B. (2007). The Severity of Supply Chain Disruptions: Design Characteristics and Mitigation Capabilities. Decision Sciences, 38(1), 131-156.

Cruz, J. M. (2013). Mitigating global supply chain risks through corporate social responsibility. International Journal of Production Research, 51(13), 3995-4010.

Dan, B., Qu, Z. J., Liu, C., Zhang, X. M., \& Zhang, H. Y. (2014). Price and Service Competition in the Supply Chain with both Pure Play Internet and Strong Bricks-andMortar Retailers. Journal of Applied Research and Technology, 12, 212-222.

Elzarka, S. M. (2013). Supply chain risk management: the lessons learned from the Egyptian 
revolution 2011. International Journal of Logistics Research and Applications, 16(6), $482-492$.

Farm, A. (2017). Pricing and price competition in consumer markets. Journal of Economics, 120(2), 119-133.

Fornari, D., Fornari, E., Grandi, S., \& Menegatti, M. (2016). Leading national brands facing store brands competition: Is price competitiveness the only thing that matters? Journal of Retailing and Consumer Services, 30, 234-241. http://doi.org/10.1016/j.jretconser.2016.02.001

Gabaix, X., Laibson, D., Li, D., Li, H., Resnick, S., \& de Vries, C. G. (2016). The impact of competition on prices with numerous firms. Journal of Economic Theory, 165, 1-24.

Giri, B. C., \& Maiti, T. (2014). Service competition in a supply chain with two retailers under service level sensitive retail price and demand. International Journal of Management Science and Engineering Management, 9(2), 133-146.

Guéant, O., Lehalle, C. A., \& Fernandez-Tapia, J. (2013). Dealing with the inventory risk: A solution to the market making problem. Mathematics and Financial Economics, 7(4), 477-507.

He, B., Huang, H., \& Yuan, K. (2016). Managing supply disruption through procurement strategy and price competition. International Journal of Production Research, 54(7), 1980-1999.

Hishamuddiin, H., Sarker, R., \& Essam, D. (2015). A simulation model of a three echelon supply chain system with multiple suppliers subject to supply and transportation disruptions. IFAC Proceedings Volumes (IFAC-PapersOnline), 48(3), 2036-2040. https://doi.org/10.1016/j.ifacol.2015.06.388

Hishamuddin, H. (2013). Optimal Inventory Policies for Multi-Echelon Supply Chain Systems with Disruption. The University of New South Wales, Canberra, Australia.

Ho, W., Zheng, T., Yildiz, H., \& Talluri, S. (2015). Supply chain risk management: a literature review. International Journal of Production Research, 53(16), 5031-5069.

Hoffmann, P., Schiele, H., \& Krabbendam, K. (2013). Uncertainty, supply risk management and their impact on performance. Journal of Purchasing and Supply Management, 19(3), 199-211. Journal Article.

Hua, G., Wang, S., \& Cheng, T. C. E. (2010). Price and lead time decisions in dual-channel supply chains. European Journal of Operational Research.

Huang, C., Yu, G., Wang, S., \& Wang, X. (2006). Disruption Management for Supply Chain Coordination With Exponential Demand Function. Acta Mathematica Scientia, 26(4), 655-669.

Huang, S., Yang, C., \& Zhang, X. (2012). Pricing and production decisions in dual-channel supply chains with demand disruptions. Computers and Industrial Engineering, 62(1), 70-83. 
Huang, W., \& Swaminathan, J. M. (2009). Introduction of a second channel: Implications for pricing and profits. European Journal of Operational Research.

Jabbarzadeh, A., Fahimnia, B., Sheu, J.-B., \& Moghadam, H. S. (2016). Designing a supply chain resilient to major disruptions and supply/demand interruptions. Transportation Research Part B: Methodological, 94, 121-149.

Jonsson, P., Rudberg, M., \& Holmberg, S. (2013). Centralised supply chain planning at IKEA. Supply Chain Management: An International Journal, 18(3), 337-350.

Kaufmann, R. K. (2016). Price differences among crude oils: The private costs of supply disruptions. Energy Economics, 56, 1-8.

Kim, K. K., \& Park, K. S. (2014). Transferring and sharing exchange-rate risk in a risk-averse supply chain of a multinational firm. European Journal of Operational Research.

Kleindorfer, P. R., \& Saad, G. H. (2005). Managing Disruption Risks in Supply Chains. Production and Operations Management, 14(1), 53-68.

Knemeyer, A. M., Zinn, W., \& Eroglu, C. (2009). Proactive planning for catastrophic events in supply chains. Journal of Operations Management, 27(2), 141-153. Journal Article.

Koblen, I., \& Lestyánszka Škůrková, K. (2015). Selected Aspects Of The Risk In The Supply Chain In Context Of The Supplier Quality Management. Research Papers Faculty of Materials Science and Technology Slovak University of Technology, 23(36), 167-178.

Kumar, A., Luthra, S., Khandelwal, D.K., Mehta, R., Chaudhary, N., \& Bhatia, S. (2017).

Measuring and improving customer retention at authorised automobile workshops after free services, Journal of Retailing and Consumer Services,39, 93-102. https://doi.org/10.1016/j.jretconser.2017.07.007.

Kuo, Y.-K. (2013). Organizational commitment in an intense competition environment. Industrial Management \& Data Systems, 113(1), 39-56.

Lee, S.-H. (2015). Order allocation to cluster suppliers considering supply failure, multiple price discount, and supplier maintenance cost. Journal of Industrial and Production Engineering, 32(8), 528-537.

Li, L., Jiang, L., \& Liu, L. (2012). Service and price competition when customers are naive. Production and Operations Management, 21, 747-760.

Li, L., Jiang, L., \& Liu, L. (2012). Service and Price Competition When Customers Are Naive. Production and Operations Management, 21(4), 747-760.

Lin, H. J. (2016). Investing in lead-time variability reduction in a collaborative vendor-buyer supply chain model with stochastic lead time. Computers and Operations Research, 72, 43-49.

Lin, M., Li, S., \& Whinston, A. B. (2011). Innovation and Price Competition in a Two-Sided Market. Journal of Management Information Systems, 28(2), 171-202.

Liu, C., Lee, C. K. M., \& Choy, K. L. (2016). Sales effort deployment in decentralized dualchannel distribution. Industrial Management \& Data Systems, 116(4), 821-837. 
Liu, Z., \& Nagurney, A. (2011). Supply chain outsourcing under exchange rate risk and competition. Omega.

Lowengart, O., \& Mizrahi, S. (2001). Retailers' control of reference price given product category and level of competition. The International Review of Retail, Distribution and Consumer Research, 11(4), 377-394.

Lu, J.-C., Tsao, Y.-C., \& Charoensiriwath, C. (2011). Competition under manufacturer service and retail price. Economic Modelling, 28(3), 1256-1264.

Lu, J.-C., Tsao, Y.-C., Charoensiriwath, C., \& Dong, M. (2012). Dynamic decision-making in a two-stage supply chain with repeated transactions. International Journal of Production Economics, 137(2), 211-225.

Lu, J. C., Tsao, Y. C., \& Charoensiriwath, C. (2011). Competition under manufacturer service and retail price. Economic Modelling, 28, 1256-1264.

Mahmoodi, A., \& Eshghi, K. (2014). Price competition in duopoly supply chains with stochastic demand. Journal of Manufacturing Systems, 33(4), 604-612.

Mills, D. J., Adhuri, D. S., Phillips, M. J., Ravikumar, B., \& Padiyar, A. P. (2011). Shocks, recovery trajectories and resilience among aquaculture-dependent households in posttsunami Aceh, Indonesia. Local Environment, 16(5), 425-444.

Murali, S., Pugazhendhi, S., \& Muralidharan, C. (2016). Modelling and Investigating the relationship of after sales service quality with customer satisfaction, retention and loyalty - A case study of home appliances business. Journal of Retailing and Consumer Services, 30, 67-83. http://doi.org/10.1016/j.jretconser.2016.01.001.

Nagurney, A., Saberi, S., Shukla, S., \& Floden, J. (2015). Supply chain network competition in price and quality with multiple manufacturers and freight service providers. Transportation Research Part E: Logistics and Transportation Review, 77, 248-267.

Natarajarathinam, M., Capar, I., \& Narayanan, A. (2009). Managing supply chains in times of crisis: a review of literature and insights. International Journal of Physical Distribution \& Logistics Management, 39(7), 535-573.

Neiger, D., Rotaru, K., \& Churilov, L. (2009). Supply chain risk identification with valuefocused process engineering. Journal of Operations Management, 27(2), 154-168.

Nishat Faisal, M., Banwet, D. K., Shankar, R., Mohd Nishat, F., Banwet, D. K., Ravi, S., ... Shankar, R. (2007). Information risks management in supply chains: an assessment and mitigation framework. Journal of Enterprise Information Management, 20(6), 677-699.

Norrman, A., \& Jansson, U. (2004). Ericsson's proactive supply chain risk management approach after a serious sub-supplier accident. International Journal of Physical Distribution \& Logistics Management, 34(5), 434-456. Journal Article. https://doi.org/doi:10.1108/09600030410545463

Oehmen, J., Ziegenbein, A., Alard, R., \& Schönsleben, P. (2009). System-oriented supply chain risk management. Production Planning \& Control, 20(4), 343-361. 
Opornsawad, C., Srinon, R., \& Chaovalitwongse, W. (2013). Competing Suppliers under Price Sensitive Demand with a Common Retailer. Proceedings of the World Congress on Engineering, $I$.

Pal, B., Sana, S. S., \& Chaudhuri, K. (2012). A multi-echelon supply chain model for reworkable items in multiple-markets with supply disruption. Economic Modelling, 29(5), 1891-1898.

Pal, B., Sana, S. S., \& Chaudhuri, K. (2014). A multi-echelon production-inventory system with supply disruption. Journal of Manufacturing Systems.

Papadakis, I. S., \& Ziemba, W. T. (2001). Derivative Effects of the 1999 Earthquake in Taiwan to U.S. Personal Computer Manufacturers. In P. R. Kleindorfer \& M. R. Sertel (Eds.), Mitigation and Financing of Seismic Risks: Turkish and International Perspectives (pp. 261-276). Dordrecht: Springer Netherlands.

Paul, S. K., Sarker, R., \& Essam, D. (2014a). Managing real-time demand fluctuation under a supplier-retailer coordinated system. International Journal of Production Economics, 158, 231-243.

Paul, S. K., Sarker, R., \& Essam, D. (2014b). Real time disruption management for a twostage batch production-inventory system with reliability considerations. European Journal of Operational Research, 237(1), 113-128.

Paul, S. K., Sarker, R., \& Essam, D. (2015a). A disruption recovery plan in a three-stage production-inventory system. Computers \& Operations Research, 57, 60-72.

Paul, S. K., Sarker, R., \& Essam, D. (2015b). Managing disruption in an imperfect production-inventory system. Computers and Industrial Engineering, 84, 101-112.

Paul, S. K., Sarker, R., \& Essam, D. (2016a). A reactive mitigation approach for managing supply disruption in a three-tier supply chain. Journal of Intelligent Manufacturing, In press, 1-17. https://doi.org/10.1007/s10845-016-1200-7

Paul, S., Sarker, R., \& Essam, D. (2016b). Managing risk and disruption in production inventory and supply chain systems: A review. Journal of Industrial and Management Optimization, 12(3), 1009-1029.

Paul, S. K., Sarker, R., \& Essam, D. (2017). A quantitative model for disruption mitigation in a supply chain. European Journal of Operational Research, 257(3), 881-895.

Peck, H. (2006). Reconciling supply chain vulnerability, risk and supply chain management. International Journal of Logistics, 9(2), 127-142.

Qin, F., Rao, U. S., Gurnani, H., \& Bollapragada, R. (2014). Role of Random Capacity Risk and the Retailer in Decentralized Supply Chains with Competing Suppliers. Decision Sciences, 45(2), 255-279. https://doi.org/67

Rogers, H., Srivastava, M., Pawar, K. S., \& Shah, J. (2016). Supply chain risk management in India - practical insights. International Journal of Logistics Research and Applications, 19(4), 278-299. 
Roy, A., Sana, S. S., \& Chaudhuri, K. (2015). Optimal Pricing of competing retailers under uncertain demand-a two layer supply chain model. Annals of Operations Research. http://doi.org/10.1007/s10479-015-1996-0.

Samvedi, A., Jain, V., \& Chan, F. T. S. (2013). Quantifying risks in a supply chain through integration of fuzzy AHP and fuzzy TOPSIS. International Journal of Production Research, 51(8), 2433-2442. Journal Article.

Sarkar, D. N., Kundu, K., \& Chaudhuri, H. R. (2016). Constructing a conceptual model of purchase behaviour of village shopkeepers - a study of small rural retailers in Eastern India. Journal of Retailing and Consumer Services, 28, 1-16. http://doi.org/10.1016/j.jretconser.2015.08.007.

Sana, S.S. (2011a). Price-sensitive demand for perishable items - An EOQ model. Applied Mathematics and Computation, 217(13), 6248-6259.

http://doi.org/10.1016/j.amc.2010.12.113.

Sana, S. S. (2011b). An EOQ model for salesmen's initiatives, stock and price sensitive demand of similar products - A dynamical system. Applied Mathematics and Computation, 218(7), 3277-3288. http://doi.org/10.1016/j.amc.2011.08.067.

Sana, S.S. (2012).An EOQ Model for Nonconforming Quality Products, Service Science, 4(4), 331-348.

Schmitt, T. G., Kumar, S., Stecke, K. E., Glover, F. W., \& Ehlen, M. A. (2017). Mitigating disruptions in a multi-echelon supply chain using adaptive ordering. Omega, 68, 185198.

Siddiqi, D. M. (2015). Starving for Justice: Bangladeshi Garment Workers in a "Post-Rana Plaza"World. International Labor and Working-Class History 8, 87, 165-173.

Singhal, K., \& Singhal, J. (2012). Imperatives of the science of operations and Supply-chain management. Journal of Operations Management.

Soyee, C., \& Small, C. (2016). Observations of cyclone-induced storm surge in coastal Bangladesh. Journal of Coastal Research, 32(5), 1149-1161.

Srivastava, S. K., Chaudhuri, A., \& Srivastava, R. K. (2015). Propagation of risks and their impact on performance in fresh food retail. The International Journal of Logistics Management, 26(3), 568-602.

Tang, C. S. (2006). Perspectives in supply chain risk management. International Journal of Production Economics, 103(2), 451-488. https://doi.org/10.1016/j.ijpe.2005.12.006

Tang, C. S. (2007). Robust strategies for mitigating supply chain disruptions. Internation Journal of Logistics Research and Applications: A Leading Journal of Supply Chain Management, 9(1), 33-45.

Tang, O., \& Nurmaya Musa, S. (2011). Identifying risk issues and research advancements in supply chain risk management. International Journal of Production Economics, 133(1), 25-34. https://doi.org/10.1016/j.ijpe.2010.06.013 
Tomlin, B. (2006). On the Value of Mitigation and Contingency Strategies for Managing Supply Chain Disruption Risks. Management Science, 52(5), 639-657.

Tsay, A. A., \& Agrawal, N. (2004a). Channel conflict and coordination in the E-commerce age. Production and Operations Management, 13, 93-110.

Tsay, A. A., \& Agrawal, N. (2004b). Channel Conflict and Coordination in the E-Commerce Age. Production and Operations Management, 13(1), 93-110.

Tsay, A. a, \& Agrawal, N. (2000). Channel Dynamics Under Price and Service Competition. Manufacturing \& Service Operations Management, 2(4), 372-391.

Tse, Y. K., Matthews, R. L., Hua Tan, K., Sato, Y., \& Pongpanich, C. (2016). Unlocking supply chain disruption risk within the Thai beverage industry. Industrial Management \& Data Systems, 116(1), 21-42.

Tweed, F., \& Walker, G. (2011). Some lessons for resilience from the 2011 multi-disaster in Japan. Local Environment, 16(9), 937-942.

Wakolbinger, T., \& Cruz, J. M. (2011). Supply chain disruption risk management through strategic information acquisition and sharing and risk-sharing contracts. International Journal of Production Research, 49(13), 4063-4084.

Wang, W., \& Sun, H. (2011). Price competition of supply chains under demand uncertainty. Journal of System and Management Sciences, 1(6), 27-37.

Wang, Y. R. (2006). Price competition in the chinese pharmaceutical market. International Journal of Health Care Finance and Economics, 6(2), 119-129.

Wenlong, C., Huijun, S., Wang, W., \& Wu, J. (2013a). Price competition model in decentralized and centralized supply chains with demand disruption. Journal of Industrial Engineering and Management, 6(1), 16-24.

Willart, S. P. C. (2015). Price competition in retailing: The importance of the price density function. Journal of Retailing and Consumer Services, 26, 125-132. http://doi.org/10.1016/j.jretconser.2015.06.003

Xiao, T., \& Choi, T. (2010). Competitive Capacity and Price Decisions for Two Build-toOrder Manufacturers Facing Time-Dependent Demand. IEE Transactions on Systems, Man, and Cybernatics, 40(3), 583-595.

Xiao, T., \& Qi, X. (2008). Price competition, cost and demand disruptions and coordination of a supply chain with one manufacturer and two competing retailers. Omega, 36(5), 741-753.

Xiao, T., Qi, X., \& Yu, G. (2007). Coordination of supply chain after demand disruptions when retailers compete. International Journal of Production Economics, 109(1-2), 162179.

Xiao, T., \& Yu, G. (2006). Supply chain disruption management and evolutionarily stable strategies of retailers in the quantity-setting duopoly situation with homogeneous goods. European Journal of Operational Research, 173(2), 648-668. 
Xiao, T., Yu, G., Sheng, Z., \& Xia, Y. (2005). Coordination of a Supply Chain with OneManufacturer and Two-Retailers Under Demand Promotion and Disruption Management Decisions. Annals of Operations Research, 135(1), 87-109.

Yan, R., \& Pei, Z. (2009). Retail services and firm profit in a dual-channel market. Journal of Retailing and Consumer Services, 16, 306-314.

Yang, D., Jiao, J. (Roger), Ji, Y., Du, G., Helo, P., \& Valente, A. (2015). Joint optimization for coordinated configuration of product families and supply chains by a leader-follower Stackelberg game. European Journal of Operational Research, 246(1), 263-280.

Yang, S.-L., \& Zhou, Y.-W. (2006). Two-echelon supply chain models: Considering duopolistic retailers' different competitive behaviors. International Journal of Production Economics, 103(1), 104-116.

Yang, S., Shi, C., Yibin, Z., \& Zhu, J. (2014). Price competition for retailers with profit and revenue targets. Internation Journal of Production Economics, 154, 233-242.

Yu, Y., Chu, F., \& Chen, H. (2009). A Stackelberg game and its improvement in a VMI system with a manufacturing vendor. European Journal of Operational Research. https://doi.org/10.1016/j.ejor.2007.10.016

Yuen, E. F. T., \& Chan, S. S. L. (2010). The effect of retail service quality and product quality on customer loyalty. Journal of Database Marketing \& Customer Strategy Management, $17,222-240$.

Zhang, G., Fang, S., \& Lai, K. K. (2015). Game Analysis in a Dual Channels System with Different Power Structures and Service Provision. Journal of Systems Science and Information, 3(6), 513-524.

Zhao, J., Liu, W., \& Wei, J. (2013). Competition under manufacturer service and price in fuzzy environments. Knowledge-Based Systems.

Zhao, J., \& Wei, J. (2012). Pricing game of two substitutable products supply chains under centralized and decentralized decisions. Journal of the Chinese Institute of Industrial Engineers, 29(7), 435-443. 